\title{
LITERATURA Y LITERATOS ESPAÑOLES \\ EN LA REVISTA LES MATINÉES ESPAGNOLES (MADRID-PARÍS, 1883-1888)*
}

\author{
FRANCISCO LAFARGA \\ Universitat de Barcelona
}

\section{Resumen}

Descripción y estudio de los artículos de escritores españoles que aparecieron en la revista Les Matinées Espagnoles, publicada entre Madrid y París de 1883 a 1888 (antes de convertirse en la Nouvelle Revue Internationale), que contó entre sus colaboradores habituales a personajes como E. Castelar y E. Pardo Bazán. La revista, dirigida por Marie Létizia de Rute y con la mayoría de textos en francés, no ha sido usualmente considerada española, extremo que el autor intenta asimismo justificar.

Palabras clave: Prensa, España, Siglo XIX, Literatura

\begin{abstract}
Description and study of the articles of Spanish writers who appeared in the magazine Les Matinées Espagnoles published between Madrid and Paris from 1883 to 1888 (before turning into the Nouvelle Revue Internationale), that counted amongst its habitual collaborators prominent figures such as E. Castelar and E. Pardo Bazán. The magazine directed by Marie Létizia de Rute and with the majority of texts in French, has not usually been considered to be Spanish, something that the author tries to also justify.
\end{abstract}

Keywords: Press, Spain, 19th century, Literature

* Este trabajo se ha realizado en el marco del proyecto de investigación FFI2012-30781, financiado por el Ministerio de Economía y Competitividad.

Anales, 26, 2014, pp. 239-256

DOI: 10.14198/ALEUA.2014.26.10 
La primera cuestión que puede plantearse el lector de este estudio -y que yo mismo me he planteado, por supuesto- es si Les Matinées Espagnoles ${ }^{1}$ es una revista «española» y «literaria». Es obvio que la demostración de ambos extremos es imprescindible para justificar su inclusión en un volumen que se titula precisamente Revistas españolas e hispanoamericanas (1869-1914) y que se incluye en una revista de ámbito literario.

El carácter español de dicha publicación no puede justificarse por el propio título, aunque aporta algún indicio. De hecho, su fundadora y directora, Marie Létizia de Rute ${ }^{2}$, había ya utilizado denominaciones similares para otros periódicos que había creado con anterioridad, Les Matinées d'Aix-les-Bains (1858-1861) y, sobre todo, Les Matinées Italiennes (1868-1873). En este caso, que es el que ofrece mayor paralelismo con el que nos ocupa, la adscripción geográfica juega un papel preponderante, a despecho de la lengua en que está redactada la cabecera, aunque es cierto que el adjetivo, tanto en el caso español como en el italiano, alude -también-a los contenidos. Por otra parte, otros indicios juegan a favor de la adscripción española.

1. El primer número de Les Matinées Espagnoles apareció en Madrid el 15 de enero de 1883; llevaba como subtítulo Nouvelle Revue Internationale Européenne. El número correspondiente al 30 de mayo de 1888 apareció con los títulos intercambiados: pasó a denominarse Nouvelle Revue Internationale, conservando como subtítulo Les Matinées Espagnoles, que perdió definitivamente en 1896. Con todo, la dirección siguió a cargo de Marie Létizia de Rute, hasta su fallecimiento en febrero de 1902, y la revista mantuvo, con ligeras modificaciones, sus características iniciales. El cambio de título justifica -en mi opinión- la consideración de dos etapas diferenciadas: así lo entiende, por ejemplo, el catálogo de la Bibliothèque nationale de France, que consagra una entrada independiente para cada etapa. Sobre esta publicación pueden verse los trabajos de Lafarga (2013 a y b) y de Irvine (en prensa).

2. Marie Létizia de Rute (1831-1902), de soltera Marie-Létizia Bonaparte-Wyse, era nieta de Luciano Bonaparte. Su vida fue bastante novelesca: se casó en tres ocasiones (con el conde alsaciano F. de Solms, con Urbano Rattazzi, ministro del reino de Cerdeña y uno de los artífices de la unidad italiana, y con el ingeniero y político español Luis de Rute y Giner). Enemistada con su tío Napoleón III, le fue prohibido residir en Francia durante el II Imperio, que pasó entre Saboya e Italia; a partir de su tercera boda vivió entre París y Madrid, manteniendo una intensa vida social. Es autora de numerosos relatos, poemas y libros de viajes y crónicas, que firmó con sus diferentes nombres de casada (Marie de Solms, Mme Rattazzi, Marie Létizia de Rute), acompañados a veces del tratamiento de princesa, que le correspondía por su abuelo, o de condesa, que le venía por alianza. Utilizó asimismo varios seudónimos (barón Stock, vizconde de Albens, Camille Bernard, vizconde de Tresserve, Louis de Kelner): la BnF rechaza diecisiete formas posibles y conserva como forma internacional la de Marie Rattazzi. Se encuentran datos biográficos sobre ella en varios textos de la época: de E. Sue (1857), A. Vitu (1869), J. H. Browne (1875), P. Larousse (1875) o C. Delaville (1887). Entre las obras modernas, de corte biográfico: Martini (1957), Bonaparte-Wyse (1969), Fouque (1999) y Aránega \& Serrano (2012). Con mayor insistencia en lo literario, aunque vinculados con su etapa saboyana, son los estudios de Secret (1935) y Harsany (1983). 
En las declaraciones de la propia fundadora en la cena de inauguración ofrecida en su palacete de Madrid, ampliamente difundida por la prensa, se insiste en la necesidad de crear en España una revista escrita en lengua francesa, a semejanza de las que ya existían en otras capitales europeas. Al no haber una declaración programática, la crónica de dicha celebración, que contó con la flor y nata de la prensa y la cultura ${ }^{3}$, ofrece algunos elementos de su postura:

Laccueil que vous faites à mes chères Matinées m'est un présage heureux de l'avenir que je m'efforcerai de leur mériter. Je bois, donc, à la presse de tous les pays, de toutes les nuances, et en particulier à la presse espagnole, cette sœur aînée de notre revue, qui l'accueille à son aurore comme une fille de dilection de cette race latine si vaillante, si forte, si admirable, et dont je vois autour de cette table les plus illustrés représentants. (1883-I: 101) ${ }^{4}$

Por otra parte, las indicaciones de tipo bibliográfico aportan elementos a tener en cuenta. Si se examinan las portadas de los distintos números ${ }^{5}$, se aprecia que en el pie de imprenta de los correspondientes a 1883 se indica «Madrid Baron Stock - Calle Montalbán, 2», que era la dirección de la directora, quien utilizó para esta publicación periódica, como había hecho en ocasiones anteriores, el citado seudónimo masculino. En la misma portada aparece el escudo de España, mientras que al final del número consta el impresor: para el primer semestre de dicho año el Establecimiento Tipográfico de los Sucesores de Rivadeneyra (Madrid) y para el segundo la Imprimerie de D. Jouaust y J. Sigaux

3. Aun cuando la mayoría de los periódicos que he consultado, en particular La Época y La Correspondencia de España, cuyos directores se sentaron junto a la anfitriona, saludaron con entusiasmo la aparición de la nueva revista, hubo alguna voz discordante, como la de Pedro Bofill en La Ilustración Artística de Barcelona, quien comienza su crónica de este modo: «Un barón que no es varón ha empezado a publicar un periódico español que no está escrito en lengua española», se burla del nombre (por el carácter poco madrugador de los madrileños) y cuestiona la incidencia de la revista en función del conocimiento del francés en España, por lo que aconseja a la directora que regale a cada subscriptor un diccionario (II, $\mathrm{n}^{\circ} 57$, de 29.01.1883, p. 34).

4. Dado que los ejemplares de la revista aparecen encuadernados en volúmenes semestrales en las colecciones conservadas, las referencias en este trabajo incluirán año, volumen y paginación.

5. Con todo, como suele ser habitual, en el proceso de encuadernación se han suprimido las portadas y otras páginas (de anuncios o de comunicados) de los diferentes números que componen los volúmenes, a veces reunidos al final de los mismos. El modo más cómodo de acceder al texto de la revista es a través de la versión digitalizada de la Bibliothèque nationale de France (Gallica, <www.gallica.bnf.fr>), aunque es incompleta, pues falta todo el año 1887. La Biblioteca Nacional de España, así como la Universidad Complutense de Madrid, poseen en papel la mayor parte de los números. Agradezco a Irene Atalaya las notas tomadas para este estudio de uno de los volúmenes de 1887, conservado en la UCM.

Anales, 26, 2014, pp. 239-256 
(París). El volumen del primer semestre de 1884 presenta un pie de imprenta más complejo, pues incluye cuatro menciones: «Madrid (Palais Altamira, 18, San Bernardo); Lisbonne (228, Rua S. Benito, chez G. Torrezao); Paris (5, rue Logelbach, Parc Monceau); Rome (Chez Bocca)», con la añadidura de la imprenta: Tipografía de Álvarez Hermanos (Madrid) ${ }^{6}$. Ya no aparece el escudo de España, sino el del impresor Damase Jouaust (un ancla con la divisa «Occupa Portum»). En los volúmenes sucesivos (entre el segundo de 1884 y el primero de 1888) el pie de imprenta queda reducido a las menciones de Madrid y París. Notaré de paso que siempre es Madrid la ciudad que aparece en primer lugar en la localización del pie de imprenta, indistintamente de la empresa que imprimiera los números ${ }^{7}$. Un último dato: en el catálogo de la Bnf la revista aparece localizada en Madrid; en el de la BNE en París y en el de la UCM en «París, etc.».

Sirva todo lo antedicho para justificar el carácter «español» de Les Matinées, justificación que quedaría reforzada con el análisis de los contenidos de la revista: en efecto, lo que podría denominarse «materia española» ocupa un lugar considerable en una publicación que se creó bajo el signo de la internacionalidad. Dicha materia está presente en los tres grandes ámbitos temáticos de la revista: la crónica, la literatura y la política.

El ámbito literario -centrado preferentemente en la actualidad-es, pues, uno de los grandes ejes de Les Matinées Espagnoles. Obviamente, el carácter internacional de la revista hace que la literatura en español o escrita por españoles comparta espacio con otras, principalmente la francesa, aunque también -en menor grado- la portuguesa y la italiana ${ }^{8}$. La propia relación de colaboradores, que de modo muy aparente se consignaba en la portada de los números -aun cuando luego no se reflejara en el interior-, presenta conocidos nombres de la cultura española del momento, como Pedro Antonio de Alarcón, Víctor Balaguer, Patrocinio de Biedma, Antonio Cánovas del Castillo, Emilio Castelar, el conde de Cheste, José Echegaray, Gaspar Núñez de Arce, Manuel del Palacio, Emilia Pardo Bazán y Juan Valera, entre otros muchos.

6. Se alude a las residencias de la directora en Madrid y París, a la de la corresponsal en Lisboa Guiomar Torrezão, activa colaboradora de la revista, y a la editorial y librería de los Fratelli Bocca en Roma.

7. En Madrid, los Sucesores de Rivadeneyra (1883-I), Álvarez Hermanos (1884-I, 1886-I, 1886-II) y M. P. Montoya (1887-I); en París, Jouaust y Sigaux (1883-II, 1884-II, 1885-I, 1885-II, 1887-II) e Imprimerie des Arts et Manufactures (1888-I). Es decir, de los once volúmenes analizados, seis se publicaron en París y cinco en Madrid.

8. Cabe decir que la revista, según afirmación de la propia directora, se sitúa en la órbita del panlitinismo, que tanto dio que hablar a finales del siglo XIX. 
Entre los géneros tradicionales, la poesía ocupa un destacado lugar en la revista, desde un punto de vista cuantitativo. A diferencia de lo que ocurre con algunos relatos, por ejemplo, los poemas se publicaron en su versión original. En este ámbito descuella, en primer lugar, el grupo formado por las tituladas «Tablettes d'Isabelle» (1883-I: 690-691 y 738-739), conjunto de poemas dedicados a Isabella Roma Rattazzi, hija de Marie Létizia de Rute, con ocasión de su decimosegundo aniversario. Se trata de doce poemas, seis de ellos en español, tres en francés y uno en catalán, italiano y portugués, respectivamente. Los poemas españoles van firmados por Antonio Romero Ortiz, Patrocinio de Biedma, J. L. Escobar, Rafael Ginard de la Rosa, Ángel de Miranda y Ramón Rodríguez Correa, mientras que el escrito en lengua catalana es de Víctor Balaguer. Se trata de poemas de circunstancias, compuestos por escritores del círculo de amistades de la directora de la revista y de su esposo. Otros poetas colaboraron asimismo en las páginas de la revista: Teodoro Guerrero, Rafael García Santisteban, Manuel del Palacio, Ernesto García Ladevese, Fernando Gabriel y Ruiz de Apodaca o Alfredo Escobar ${ }^{9}$ con textos alusivos a personas del entorno de los Rute, sus hijos o sus allegados, como Charlotte Mortier, ayudante personal de Marie Létizia y colaboradora de la revista con el seudónimo Pérégrine ${ }^{10}$.

En otro ámbito, aunque también vinculados a algún acontecimiento concreto, se encuentran los dos poemas de la infanta Paz de Borbón reproducidos junto a la larga crónica de su boda con el príncipe Luis Fernando de Baviera: uno dedicado a la Virgen de la Almudena -que cuenta, asimismo, con la traducción al francés- y otro dirigido a su madre, la reina Isabel II (1883-I:

9. T. Guerrero dirige un poema festivo a Luis de Rute (1883-I: 500) en el que se queja de que, en la lista de colaboradores que encabeza el número, se haya puesto su nombre entre los de las señoras; le sigue una disculpa, también en verso, de Rute. R. García Santisteban y M. del Palacio componen sonetos para celebrar el bautizo de $\mathrm{M}^{\mathrm{a}}$ Luisa de Rute, hija del matrimonio (1883-I: 435), a los que puede sumarse el poemita de García Ladevese incluido entre los que se dedicaron a la niña con motivo de su segundo cumpleaños (1884-II: 311). A Gabriel y Ruiz de Apodaca se debe el soneto que compuso en 1880 «A doña María Letizia Bonaparte Wyse y a D. Luis de Rute en sus bodas» (1883-I: 74), publicado junto a otro «En conmemoración de la muerte de Ayala», compuesto el mismo año (seguramente referido al escritor y político Adelardo López de Ayala, fallecido en 1879). Al citado M. del Palacio se deben asimismo los poemas dedicados a Isabel Roma Rattazzi (1884-I: 61) y a Charlotte Mortier (1884-I: 118). Finalmente, con ocasión de sus quince años, R. García Santisteban y A. Escobar dedican sendos poemas a la hija de Marie Létizia de Rute (1886-I: 46), el primero una epístola y el segundo una cuarteta.

10. En un estudio anterior (Lafarga 2013a: 242-243), basándome en distintos indicios, supuse que Pérégrine era uno de los tantos seudónimos adoptados por Marie Létizia de Rute; varias referencias halladas recientemente confirman que tras ese nombre se escondía Charlotte Mortier.

Anales, 26, 2014, pp. 239-256 
338 y 396). Igualmente, al hilo de un estudio del marqués de Valmar sobre el duque de Rivas (en realidad, insertado sin número de página tras la última entrega del estudio) se publica un largo poema en romance octosílabo de su hijo Enrique, titulado «¿Quién manda?», acerca de la relación entre el alma y el cuerpo, introducido por esta declaración:

Nous avons la fortune d'offrir à nos lecteurs des vers inédits du duc de Rivas, digne fils de son père, dont quelques inspirations au souffle élevé, à la forme impeccable, offrent peut-être, au dire de grands juges en la matière, quelque chose de plus complet encore, de plus harmonieux que les poésies de don Álvarez [sic] lui-même. Il nous a paru intéressant de mettre en regard l'une des productions du duc de Rivas, fils, avec l'étude si achevée, si parfaite du marquis de Valmar, sur le duc de Rivas, père. Ils sont si rares les grands hommes qui se poursuivent dans leurs enfants! (1887-I: s. p.)

Y unas páginas más adelante la revista ofrece dos nuevas composiciones de Enrique Ramírez de Saavedra, el poema «El beso» y un soneto dedicado a la reina María Cristina (1887-I: 332). Junto a estos, los únicos poemas desvinculados de las circunstancias son los «Cantares» de T. Guerrero, conjunto de doce cuartetas, cada una de las cuales encierra un pensamiento de tema amoroso (1883-I: 433-434).

El género teatral -menos apropiado, sin duda, para su inclusión en una revista- está representado por la pieza breve de corte cómico Política casera, subtitulada «Escenas de salón», de Rafael García y Santisteban (1883-I: 333-336), y por Asclépigénie de Juan Valera, en un acto de cierta extensión, repartido en cuatro entregas (1884-I: 109-114, 153-157, 207-210 y 259-262) y traducido al francés, según consta al final de la última entrega por «Mme L. Z. de U.», iniciales que corresponden a Luisa Zavala de Uhagón ${ }^{11}$. La obra, presentada como «Diálogo filosófico-amoroso», se había publicado en español en la Revista Contemporánea del 15 de junio de $1878^{12}$.

Con todo, la obra dramática de mayor consideración es Le grand Galeoto, traducción realizada por Marie Létizia de Rute del drama de José Echegaray, difundida en siete entregas a lo largo del primer semestre de 1883, la primera

11. Con el nombre completo aparece como traductora del amplio estudio sobre el duque de Rivas, obra del marqués de Valmar, publicado en once entregas a lo largo del segundo semestre de 1886 y del primero del año siguiente (ver referencias más adelante).

12. Tomo XV, no 61, pp. 257-278; puede leerse en el portal Filosofía en español (<http:// www.filosofia.org/hem/dep/rco/0150257.htm>). El autor la incluyó en un volumen de Tentativas dramáticas (Madrid, Benito Perojo, 1879), y más tarde se incorporó al vol. XVI de las Obras completas (Madrid, Imprenta Alemana, 1908), reproducido en la B. Virtual Miguel de Cervantes (<http://www.cervantesvirtual.com/obra/asclepigenia-1878--0/>). Hay ed. moderna con introducción de Andrés Amorós y epílogo de Manuel Azaña (Madrid, Ediciones 98, 2012). 
de las cuales contiene el prólogo de la traductora ${ }^{13}$. Antes de finalizar el año la obra se publicó en volumen, casi simultáneamente, en Madrid (Sucesores de Rivadeneyra) y en París (Librairie de la Nouvelle Revue Internationale). Ante el anuncio de una nueva versión del drama de Echegaray, se insertó esta nota en las páginas de la revista:

Justement émue de ce bruit persistant, notre collaboratrice Mme de Rute, qui a traduit depuis deux ans, avec autorisation de l'auteur, le drame en question, distribué à toute la presse depuis six mois et qu'elle s'occupe de mettre à la scène, Mme de Rute disons nous s'est empressée d'envoyer une protestation aux différents journaux qui avaient ébruité cette nouvelle. Laaffaire en était là lorsque Le Figaro, par la plume autorisée de M. Auguste Marcade, a clos en quelque sorte le conflit en ne mentionnant et ne s'occupant que de la traduction qui avait tous les droits de priorité acquis, celle de Mme de Rute. (1884-I: 140)

Y a continuación se reproduce el mencionado artículo, de 9 de febrero de 1884. La nueva traducción objeto del litigio era de Joseph Schürmann y Jacques Lemaire, y se publicó en 1896 (París, A. Charles), poco después de su representación en el Théâtre des Poètes (11 de abril). Con ello, se adelantó a la primera función de la versión de Mme de Rute, que tuvo lugar el 20 de mayo de aquel año en el Nouveau Théâtre y que contó con la actuación de Aurélien Lugné-Poë y Alice Archainbaud en los principales papeles.

En el ámbito del relato aparecieron cuatro ejemplos en estos años: Pourquoi était-elle blonde? de Pedro Antonio de Alarcón (1884-I: 249-255); Rosario del marqués de Premio Real, Ricardo de Miranda y Sandoval (1886-I: 125-129), Le petit rastaquouère de Eusebio Blasco (1888-I: 10-14) y Le bermegino préhistorique ou Les salamandres bleues de Juan Valera (1888-I: 1-5, 41-45, 73-76, 118-122, 153-157, 196-199 y 233-236). El relato de Alarcón, fechado en 1859, ya había sido publicado entre sus Cuentos amatorios, que constituían el primer volumen de sus Novelas cortas (Madrid, Tello, 1881): no consta el nombre del traductor, lo cual, obviamente, no es prueba alguna de que fuera vertido por el propio autor, contrariamente al texto de Blasco, que corresponde a la época en que estaba en París y escribía en francés. El de Alarcón contiene dos partes: en la primera el autor refiere una apuesta con cinco amigos escritores (Luis Eguílaz, Manuel del Palacio, Agustín Bonnat, Ivon [José Fernández Jiménez] y Luis Mariano de Larra) consistente en escribir cada uno un relato sobre el mismo tema; da un resumen del contenido de los cuentos de sus amigos y, por extenso, el suyo propio. El relato del marqués de Premio Real es una sombría historia (subtitulada «Épisode d'une nuit de

13. 1883-I: 197-205, 292-301, 341-346, 490-499, 591-594, 656-662 y 731-737.

Anales, 26, 2014, pp. 239-256 
Carnaval à Madrid»), que mezcla la alegría del Carnaval con la amargura de la pobreza y la muerte. Por su parte, E. Blasco relata la decadencia de un vividor jactancioso, que, tras derrochar su fortuna, termina de botones en un restaurante. En cuanto al relato de Valera, se abre con sesudas consideraciones sobre la prehistoria de la península Ibérica para pasar a una historia de amor y de aventuras ambientada en aquella lejana época, que recuerda por momentos algún cuento de Voltaire. Incluido en un volumen de Cuentos y diálogos (Sevilla, F. Álvarez y Cía., 1882), fue vertido al francés por Charlotte Mortier (Pérégrine), quien deja sin traducir la palabra «bermejino» (pelirrojo) porque las equivalencias que le habían propuesto -dice- no la satisfacían.

Varios textos se hallan en el límite de lo literario. Así, el conjunto de siete pensamientos de Manuel del Palacio reunidos, en francés, con el título de Pensées (1883-I: 243), así como las cartas desde Egipto redactadas por Mariano de Ortega Morejón en 1884 y recogidas en varios números de la revista, una con el título «Lettres d'Orient» (1884-II: 114-116) y las restantes como «Lettres d'Égypte» (1884-I: 33-35 y 1884-II: 23-24, 190-191 y 249-251) ${ }^{14}$. Varios artículos firmados por españoles son más técnicos, a modo de breves estudios de corte histórico, lingüístico o literario. Tal es el caso del titulado «Les ossements du Cid et de Chimène» de Francisco M. Tubino, fechado en abril de 1883 y publicado poco después (1883-I: 364-367 y 523-525): se trata de un resumen del opúsculo aparecido el mismo año (fechado el 9 de febrero) Los restos mortales del Cid y Jimena devueltos a España por S. A. R. el príncipe C. Antonio Hohenzollern (Sevilla, La Andalucía). En cuanto al artículo «Titin», obra del folclorista y antropólogo Antonio Machado Álvarez (Demófilo), padre de los poetas Antonio y Manuel, es un estudio sobre el lenguaje infantil, a partir de experiencias comprobadas con sus hijos José (Pepe) y Joaquín (Titín). Se publicó en francés en Les Matinées Espagnoles al inicio del segundo semestre de 1884 (II: 93-96 y 185-189), aunque, al parecer, el original español no apareció hasta 1887, en el Boletín de la Institución Libre de Enseñanza (año $\mathrm{XI}, \mathrm{n}^{\circ} 257$ y 258) con el título «Titín y las primeras oraciones. Estudio sobre el lenguaje de los niños»; por su parte, se publicó una traducción al inglés, con un título similar, en la revista Philological Society de noviembre de 1887 (vol. 20, pp. 68-74), y también se hicieron versiones al alemán y al italiano (véase Gómez-García Plata 2010: 590) ${ }^{15}$. Menos problemas de precedencia

14. Ortega Morejón, diplomático, publicó varios años más tarde un estudio sobre La administración egipcia antes y después de la ocupación inglesa (Buenos Aires, 1889).

15. Esta autora da la fecha de 1886 para la publicación de la versión inglesa y no menciona la traducción aparecida en Les Matinées Espagnoles, que habría precedido incluso a la versión española. 
plantea el estudio de Leopoldo Augusto de Cueto, marqués de Valmar, sobre su cuñado Ángel de Saavedra «Le duc de Rivas, poète et historien espagnol. Étude critique», traducido por Luisa Zavala de Uhagón ${ }^{16}$. Aunque se indica en nota que se ha escrito especialmente para Les Matinées Espagnoles, un rápido cotejo muestra lo mucho que debe al discurso que el marqués de Valmar había pronunciado en la Real Academia veinte años antes ${ }^{17}$ : se han suprimido en particular los elementos puramente orales, así como algunas citas textuales y alusiones a otros académicos.

Otros españoles colaboraron en la revista, aunque sus artículos, salvo excepciones, poco o nada tienen que ver con la literatura. El más activo fue Luis de Rute, quien se encargaba de la información de tipo político y parlamentario relativa a España, y que en una ocasión firma un artículo (acerca de las obras públicas durante la Regencia) que debía incorporarse a la serie redactada por su esposa sobre «La société de Madrid»(1887-I: 300-302, 333-335 y 430-434).

Por otra parte, y como ya ha sido mencionado más arriba, la materia española ocupa un lugar destacado en la revista. En lo que se refiere a la literatura, aparecieron varios artículos que tenían por objeto comentar la vida literaria o glosar la figura de algún literato. Entre los primeros, pueden mencionarse los dos capítulos sobre «La littérature et la science», así como el dedicado a «Les journaux et la littérature politique», que Marie Létizia de Rute incluyó en la mencionada serie sobre «La société de Madrid» (1886-I: 64-67, 98-106 y $130-138)^{18}$. En cuanto a los artículos sobre literatos, se debe a la propia Mme de Rute el dedicado a Gaspar Núñez de Arce, tremendamente elogioso, con una larga disquisición sobre el carácter de los españoles, que olvidan sus diferencias políticas cuando se trata de admirar el talento literario o artístico (1883-I: 313-316; va acompañado de un retrato insertado entre las pp. 312 y 313). También es obra de la directora la nota biográfica, acompañada de retrato, sobre el marqués de Valmar (1884-II: 240-241). Finalmente, Manuel

16. El largo estudio se publicó en once entregas (1886-II: 253-258, 293-299, 333-335, 385390, 429-432; y 1887-I: 24-29, 53-57, 97-101, 137-141, 229-234 y 281-285).

17. Discurso necrológico en elogio del Excmo. Sr. duque de Rivas, director de la Real Academia Española, leido en la junta pública celebrada para honrar su memoria (Madrid, M. Rivadeneyra, 1866).

18. De hecho, y como señala el barón Stock en una nota puesta en el primer número del año 1886, a petición de muchos amigos, decidió retomar sus crónicas que, con el título «Madrid et sa société», habían aparecido años atrás en la revista vienesa Neue Freie Press, a pesar de que en la Nouvelle Revue, dirigida por Juliette Adam en París, ya se había publicado otra serie, firmada por el conde Paul Vasili (tal vez la propia Mme Adam), que apareció en forma de libro en el transcurso de 1886. También anuncia que va a utilizar partes publicadas en su obra L'Espagne moderne (París, 1879). 
Fernández Giner, primo de Luis de Rute, es el redactor de la necrológica del dramaturgo Antonio García Gutiérrez (1884-II: 197-199).

En otro registro, cabe mencionar asimismo las obras españolas (o escritas por españoles) que fueron reseñadas -con mayor o menor atención- en la sección bibliográfica, que, salvo excepciones, aparece al final de cada número; suele ir firmada por Pérégrine, y en los casos en que falta la firma, debe atribuirse a la propia directora. En el primer semestre de 1883 se reseñaron las siguientes obras: El crimen de Villaviciosa de Ramón de Navarrete (549552); María de los Ángeles de José de Navarrete (607); Recuerdos de Edmondo d'Amicis, traducción de Hermenegildo Giner de los Ríos (740); Fábulas en acción de Teodoro Guerrero (741); Teatro cómico de Eduardo Sánchez de Castilla (741) y Versos para abanicos de Manuel Jorreto Paniagua (741). En el segundo semestre del mismo año se hallan comentarios a Cinco dramas de Shakespeare, traducidos por Guillermo Macpherson (108); Un libro sin héroe de Marcos Latasa (311) y la antología poética Granos de oro de Jaime Martí-Miquel (448). El primer semestre de 1884 es el volumen que presenta el mayor número de reseñas: Poesías de Fernando de Gabriel y Ruiz de Apodaca (103); Obras de Manuel del Palacio (103); Los lunes de El Imparcial de José Ortega Munilla (152); el ensayo La muerte y el diablo de Pompeyo Gener (247-248); el Orlando furioso de Ariosto, traducido por el conde de Cheste (407); Delle scriticci spagnuole de Emilio Alcalá-Galiano y Valencia, conde de Casa Valencia, traducido al italiano por Fanny dell'Odio Torchi (408) y Las luchas de nuestros días de Francisco Pi y Margall (465-466). Esta obra es la que merece el comentario más extenso, pues continúa en el primer número del segundo semestre (3839), que contiene asimismo la reseña de la novela El periodista de Eduardo López Bago (39). El año 1885 es flaco en reseñas de obras españolas, pues solo publicó una, sobre la versión francesa de las Légendes espagnoles de Gustavo Adolfo Bécquer, traducidas por Achille Fouquier (1885-I: 419). Remonta algo la presencia de títulos españoles en el primer semestre de 1886, con las Leyendas moriscas sacadas de varios manuscritos de Guillén Robles (123); La política de la Regencia del conde de las Almenas, o sea, Francisco Javier de Palacio (215) y La vida en Madrid de Enrique Sepúlveda (465), mientras que el segundo semestre del mismo año incluye únicamente reseñas del volumen de novelas cortas Acuarelas del marqués de Premio Real, Ricardo de Miranda y Sandoval (38) y de Le Naturalisme de Emilia Pardo Bazán, traducido por Albert Savine (470). No aparecen obras españolas en los números restantes.

A pesar de la cantidad y variedad de las presencias españolas en Les Matinées Espagnoles, hay dos autores que mantienen una participación especial en la revista: Emilio Castelar y Emilia Pardo Bazán. Ambos pertenecían al círculo 
familiar del matrimonio Rute-Bonaparte Wyse: Castelar no faltaba en los banquetes y saraos ofrecidos en el palacete madrileño de los señores de Rute, y doña Emilia redactó en 1889 un sentido artículo con motivo del fallecimiento de Luis de Rute, en el que también aludía a la muerte de su hijita María Dolores (Loló), en un tono muy íntimo y con múltiples alusiones personales y en 1902 otro no menos cercano sobre Marie Létizia con ocasión de su muerte ${ }^{19}$.

De Emilio Castelar se publicaron en la revista diecinueve artículos de temática muy variada, aparte de fragmentos de dos discursos pronunciados con ocasión de la inauguración y el segundo aniversario de las Matinées; también fue objeto de dos estudios.

Como es previsible (y ha sido comprobado en otras ocasiones) muchos textos no fueron escritos especialmente para la revista, a pesar de lo que digan las oportunas notas a pie de página. Con todo, la ingente producción de Castelar, diseminada en multitud de publicaciones periódicas y no siempre recogida en volumen, dificulta la identificación de los posibles originales ${ }^{20}$. Por tal motivo, me limitaré en estas páginas a dar cuenta de los artículos, siguiendo el orden temporal de publicación, con algún comentario en los casos en que he encontrado alguna pista.

A Castelar le cupo el honor de ser autor del primer artículo firmado aparecido en Les Matinées Espagnoles: «Reine et tribun» (1883-I: 7-8, 47-48 y 105106); con la mención de que se había escrito especialmente para la revista, trata de la conocida como «entrevista de Saint-Cloud» entre María Antonieta y Mirabeau. Castelar había incluido el episodio en el extenso prólogo que redactó para la soberbia edición de la Historia de la Revolución francesa de Adolphe Thiers, aparecida entre 1876 y $1879^{21}$. Poco más tarde se publicó «Saint Ignace et don Quichotte» (1883-I: 329-332), con la misma indicación; con

19. «A una cara memoria (Luis de Rute)», El Liberal de 25 de abril de 1889, 1-2; La Ilustración Artística n ${ }^{\circ}$ 1058, de 7 de abril de 1902, p. 2.

20. No me ha sido de mucha ayuda, por ejemplo, la abundante bibliografía insertada en el capítulo dedicado a Castelar en el Proyecto Ensayo Hispánico (<http://www.ensayistas. org>), como tampoco la lista proporcionada por Esteve (1990); solo esporádicamente alguna pesquisa por internet ha arrojado frutos. En cuanto a la redacción de los textos, todos menos uno publicados en francés, es más que probable que procedan de alguna fuente española; Esteve afirma que Castelar «siempre escribía sus artículos en castellano y, posteriormente, eran traducidos. Su atildado estilo fue un impedimento para que se decidiera a redactar en francés, pese a hablarlo con fluidez» (1990: 49 nota). Acerca de la relación de Castelar con la cultura francesa, puede consultarse el estudio de Álvarez Rubio (2012).

21. Publicada en Barcelona por Montaner y Simón; hay una segunda ed. de 1892, que es la que he consultado. El prólogo ocupa las pp. I-CLX del primer volumen, y el episodio se halla en las pp. CXXVII-CXXXI. Existe una ed. facsimilar del prólogo en Madrid, Edición Personal, 2013. 
todo, el texto está extraído de La revolución religiosa (Barcelona, Montaner y Simón, 1880-1883), el cuarto volumen de la cual versa sobre la figura de san Ignacio $^{22}$. A lo largo del primer semestre del siguiente año aparecieron: «Une scène à Florence au Xe siècle» (1884-I: 1-5), calificado de «tableau historique» y con la mención de que se ha escrito especialmente para la revista; «Un livre de M. de Blowitz» (1884-I: 201-205), comentario de la obra Une course à Constantinople (París, 1884) de Adolpe Opper de Blowitz, periodista francés nacido en Bohemia, corresponsal del Times en París; y «Un dialogue romain» (1884-I: 345-352), diálogo entre Marco Antonio y Cleopatra, el cual, aunque lleva la mención de que se ha escrito especialmente para la revista, ya se había publicado en La redención del esclavo (Madrid, San Martín y Jubera, 1875, vol. II de la $2^{a}$ parte, 234-247).

A lo largo del segundo semestre de 1884 vieron la luz: «La Hollande et les Orange» (1884-II: 1-7), fechado en San Sebastián en agosto de 188423; «Débats politico-religieux au Parlement espagnol» (1884-II: 89-92, 153-160 y 201-207), con la mención de que se trata de una serie de artículos inéditos y de que serán objeto de una publicación autónoma, que no he logrado localizar; y «La mujer» (1884-II: 272-275), que recoge el discurso pronunciado por Castelar en un banquete ofrecido por un grupo de escritores y políticos españoles a Marie Létizia de Rute. Es el único texto de Castelar en español, y en una nota previa se indica que no se ha procedido a traducirlo para conservar las bellezas del original.

El siguiente año vio la publicación de: «La mort de Cléopâtre. Dialogues romains» (1885-I: 2-9), diálogo entre la reina, su médico y dos esclavas, que es traducción de dos capítulos de la mencionada Redención del esclavo (vol. II de la $2^{a}$ parte, 331-365)24; «Les dieux de l'Antiquité dans leurs théâtres éternels» (1885-II: 113-116), que -a pesar del pomposo título-se limita a los

22. En el capítulo V, titulado «Primera peregrinación piadosa de san Ignacio de Loyola» (pp. 87-100), se alude a diversos aspectos del paralelismo entre Ignacio y don Quijote, algunos de los cuales se recogen en el texto francés.

23. Lleva la siguiente nota: «Afin de pouvoir publier l'importante étude de notre illustre collaborateur D. Emilio Castelar sur la Hollande et les Orange, nous avons dû retarder de quelques jours l'apparition de ce numéro; nos lecteurs nous sauront gré de ce retard. La reproduction et la traduction de cet article sont interdites sans la permission de l'auteur; les citations dans les journaux sont seules autorisées».

24. Sanz Morales (2004: 156) menciona el artículo «La muerte de Cleopatra. Estudio histórico-literario», aparecido en La Ilustración Española y Americana en 1898 (año XLI, $\mathrm{n}^{\circ}$ 9, de 8 de marzo, 138-140), y añade que este texto retoma ideas expuestas por el autor en la mencionada Redención del esclavo y, sobre todo, en el capítulo "Cleopatra» de su Galería histórica de mujeres célebres (Madrid, Álvarez Hnos., 1886-1889, vol. VII, pp. 59-251). 
episodios míticos de Ceix y Alcíone y de Glauco, y aunque se indica -como en tantos otros casos- que se ha escrito especialmente para la revista, ya se había publicado en El ocaso de la libertad (Madrid, Miguel Guijarro, 1877, pp. 19-28) ${ }^{25}$; y «La question des Carolines» (1885-II: 257-263), que reproduce un fragmento de un discurso pronunciado en Orense el 21 de septiembre de 1885.

Con fecha de 1886 aparecieron: «La première mort» (1886-I: 217-225), que aunque también lleva la mención de que se ha escrito especialmente para la revista, es traducción, salvo leves modificaciones en la presentación, del relato «La primera muerte. Tragedia bíblica», aparecido en La Ilustración Española y Americana en 1882 (suplemento al $\mathrm{n}^{\circ} 21$, de 8 de junio, pp. 362-263); «Un moine germain dans la Cité Éternelle» (1886-I: 312-317 y 417-421), que es traducción de «Lutero en Roma», capítulo VII del vol. II (pp. 213-226) de la obra, ya mencionada, La revolución religiosa; y «Un peu de musique» (1886-II: 177-184), comentario sobre las óperas de Wagner y de Bellini, con la mención de que se ha escrito especialmente para la revista.

Finalmente, a lo largo de 1887 se publicaron: «Paris, Juarez et le Théâtre des Nations» (1887-I: 5-6), a raíz de la representación en París, en octubre de 1886, del drama Juarez de Alfred Gassier, sobre los sucesos de México; «La divination en Grèce de l'idéal féminin» (1887-I: 142-147), con la mención de que se ha escrito especialmente para la revista; «Le campement de Grenade» (1887-I: 277-280), fechado el 1 de mayo de 1887 y con prohibición de reproducción, que es, en realidad, un fragmento de su libro El suspiro del moro. Leyendas, tradiciones, historias referentes a la conquista de Granada (Madrid, Fortanet, 1886); «Les questions d'Orient» (1887-II: 81-86), fechado en San Sebastián, en agosto de 1887, sobre el proceso de disgregación del Imperio turco, en particular por los casos de Egipto y Bulgaria, que ya había tratado en 1876 en el libro La cuestión de Oriente (Madrid, La Ilustración Española y Americana) y retomado -a raíz de la unión de Bulgaria y Rumelia- en varios artículos de La Ilustración Española y Americana de octubre de 1885; y «Sémiramis» (1887-II: 241-244, 281-283 y 321-326), que corresponde a una parte (pp. 241-266) del largo capítulo que el mismo año se publicó en el vol. III de la Galería histórica de mujeres célebres (Madrid, Álvarez Hnos.).

En cuanto a los discursos, Les Matinées incorporan dos muy vinculados a su propia historia: con motivo del lanzamiento de la revista en enero de 1883 y con ocasión del primer aniversario de la misma el año siguiente. La

25. Debo la pista al estudio de Sanz Morales (2004), quien no indica, como tampoco lo hacía en el caso de «La mort de Cléopâtre», la publicación en Les Matinées Espagnoles. 
amplia crónica del primer acontecimiento reproduce in extenso el parlamento de Castelar (1883-I: 101-103), en el que saluda el nacimiento de la nueva publicación, hace un un elogio de su directora y concluye con un llamamiento a la regeneración de España. Más breve, pero no menos elogioso, es el discurso que pronunció en 1884 para celebrar el primer año de vida de la revista (1884 I: 53-54), tras el parlamento de la directora. Y, obviamente, no podía faltar su perfil biográfico (1883-I: 649-652) acompañado de retrato, redactado por la propia Marie Létizia de Rute, que se inicia con estas palabras:

Le portrait de Castelar exigerait à lui seul tout un volume (Je ne le tenterai pas). L'amitié que j'éprouve pour lui est trop grande pour que j'en puisse parler en toute effusion de coeur; je n'excéderais pas les limites de l'impartialité si je disais de lui, tout le bien que j'en pense: on me croirait partiale. Ensuite, comme il est non seulement un homme d'État et un homme de lettres, mais encore un savant et un artiste, il n'est guère de sujet auquel on puisse toucher sans rencontrer son nom sous sa plume. Le meilleur, le seul éloge d'un homme si merveilleusement doué, est de le nommer. Il y a des noms qui valent tout un livre.

Un último apunte: en el artículo «Un voyage féérique. Tolède et Castelar» (1886-I: 325-329) Mme de Rute relata una excursión a Toledo que Castelar había ofrecido como regalo de bodas a unos recién casados, y comenta en una nota inicial:

Don Emilio Castelar a toutes les inspirations du cœur et du génie. Il a offert à la jeune compagne et protégée d'une amie très chère dont il était le parrain de mariage [...] le cadeau le plus original et le plus flatteur qui se puisse offrir: un voyage à Tolède au lendemain des noces, dans des conditions exceptionnelles, avec un entourage d'élite et plus encore, lui-même pour cicérone. Certes, voilà un souvenir de toute la vie pour les nouveaux époux auxquels Castelar a consacré deux jours entiers, deux jours, vous entendez bien, lui, le grand orateur, le grand ex-président de la République.

En cuanto a Pardo Bazán, si bien su presencia no es tan abultada, no por ello resulta menos interesante. Dio a la revista siete textos, y se publicó un artículo sobre ella y una larga mención a su personalidad en otro artículo. El primer texto que apareció fue el relato «Un petit fils du Cid» (1883-II: 110114) -narración del asalto de unos ladrones a la casa de un cura de pueblo en su Galicia natal- precedido por la siguiente nota: «Mme Emilia Pardo Bazán, dont nous publions aujourd'hui cette page saisissante écrite spécialement pour les Matinées Espagnoles, est actuellement la George Sand de l'Espagne. Sa réputation grandit chaque jour; nous étudierons prochainement cette originale et puissante personnalité». A pesar de lo expresado, el relato en francés (fechado el 9 de agosto de 1883 y publicado en el número del mismo mes) 
fue escrito con posterioridad a su versión en español, que lleva fecha de 9 de julio, aunque este se publicó poco después del otro, en la Revista Ibérica del 16 de septiembre (pp. 267-270), antes de formar parte del volumen La dama joven y otros cuentos (Barcelona, Cortezo, 1886, «Biblioteca Arte y Letras»). Se trataría, según E. Pérez Romero (en prensa) de un caso de autotraducción ${ }^{26}$. El segundo artículo es el titulado «Sesión flamenca» (1886-I: 81-85), en el que $\mathrm{D}^{\mathrm{a}}$ Emilia describe un cuadro flamenco en un ambiente foráneo, presumiblemente francés; el texto se acompaña de una decena de notas explicativas de palabras conservadas en español en el texto ${ }^{27}$. Por su parte, el artículo «Le barde Eduardo Pondal» (1887-I: 325-331) es un entusiasta estudio de la obra y el carácter poético de su coterráneo, mientras que «Le salon de 1887» (1887-I: 369-374 y 417-421) constituye una extensa crónica de la Exposición de Bellas Artes de Madrid. Los otros tres artículos de $D^{a}$ Emilia son, en realidad, tres episodios de su viaje a Italia con motivo del jubileo sacerdotal de León XIII: «Guelfes et Gibelins», sobre el debate acerca del papel del Vaticano en la Italia moderna (1888-I: 113-117), «Un cicerone gratis», paseo por Roma de la mano del pintor y dibujante Luis Llanos (1888-I: 158-161) y «Journée florentine», relato de una breve visita a Florencia (1888-I: 193-195). Estos tres episodios no fueron publicados por El Imparcial, periódico al que Pardo Bazán envió varias crónicas de su viaje, sino que se incluyeron en el volumen Mi romería (Madrid, Tello, 1888), que según Jiménez Romero (2007: 158, n. 11) debió aparecer en el mes de abril, ya que el propio Imparcial ofrece el anuncio el 7 de mayo. Si así fue, los lectores pudieron tener acceso antes a la versión francesa que a la española, pues la primera crónica apareció en la edición del 5 de marzo, la segunda en la del 7 de abril y la tercera en la del 30 del mismo mes.

En cuanto a los textos acerca de Pardo Bazán, un breve comentario sobre uno de sus viajes a París se halla en una «Lettre parisienne» firmada por el vizconde d'Albens, seudónimo de Mme de Rute (1885-I: 276-277), precedido, el año anterior, por el perfil biográfico, sin firma, o sea, debido a la propia directora de la revista, y acompañado del retrato de la escritora (1884-I: 99100). Este texto es altamente elogioso e intenta plasmar la imagen, tanto física

26. Agradezco a Emilia Pérez Romero el envío de una copia de su trabajo inédito; sobre esta y otras colaboraciones de Pardo Bazán a la revista puede verse el trabajo de la misma autora (2010). No es el único caso de autotraducción que ha sido estudiado (véase McDermott 2009).

27. Pérez Romero, que comenta este artículo (2010: 5-6), precisa que una versión reducida del mismo se incluyó en el volumen monográfico L'Espagne (1900) publicado por la Nouvelle Revue Internationale, y que la versión en español apareció en la revista El Museo Popular de 1886 (tomo I, n² 2, pp. 2-4 y tomo II, no 3, pp. 1-3). 
como intelectual, de la denominada, en otros lugares de la revista, la segunda Fernán Caballero, o la George Sand española:

Un bas bleu? Non! Une femme qui met au service d'un esprit profond, subtil et délicat un style puissant et coloré. [...] Au physique, c'est une des duchesses ou des dogaresses, peintes par Van Dick et par Moro. Yeux et cheveux noirs, regards langoureux, bien qu'ayant une certaine malignité causée par le clignement de la myopie, nez aquilin, aux narines mobiles, menton accusé, teint chaud, Doña Emilia a l'extérieur le plus agréable et le plus sympathique. [...] Elle domine les horizons merveilleux de la pensée; elle parcourt d'un pas assuré les vastes champs que l'imagination peuple des chimères. Non seulement elle cultive la muse, mais encore la philosophie. Létude des mathématiques, des sciences naturelles, des langues vivantes et des langues mortes occupent les loisirs que lui laissent sa vie de famille. (1884-I: 99)

El balance que este recorrido arroja sobre la presencia de las letras españolas en Les Matinées Espagnoles, resulta -a mi entender- altamente positivo. La colaboración de muchos de los grandes nombres de la cultura española del momento aportó una garantía de calidad a la revista en el propio mercado español: en efecto, cuesta creer que, aparte del celebérrimo Castelar o de Pardo Bazán, se conociera en Francia, o en otros países, a todos ellos. Precisamente, uno de los objetivos de Marie Létizia de Rute al fundar la revista era dar a conocer en Europa, y en particular en Francia, la literatura española:

Je me proposais simplement de faire connaître en Europe les œuvres hors pair de quelques écrivains espagnols, portugais, italiens; d'étendre extra muros leur renommée, c'est-à-dire, d'obtenir pour eux la chose la plus difficile à obtenir, quelque illustration que l'on possède dans son pays, par le temps d'agitation, de fièvre et de dégoût dans lequel nous vivons l'attention de l'étranger. Je voulais, en un mot, en les faisant connaître et en les imposant à l'examen du public littéraire européen, triompher de l'indifférence, de l'ignorance coupable des Français pour la littérature des pays voisins, indifférence contre laquelle j'ai toujours protesté. J'ai réussi, je le crois du moins. (1884-I: 51)

Para dicho propósito, el recurso al francés como lengua vehicular era, si no ineludible, altamente aconsejable. Por otra parte, la redacción en esa lengua no anulaba -como en el caso de otros periódicos publicados en Italia, Alemania o Rusia- su carácter «nacional», y así lo afirmaron en más de una ocasión los responsables de la revista. Con todo, a Les Matinées Espagnoles no se les reconoce todavía su lugar en la historia de la prensa española. 


\section{Bibliografía citada}

Álvarez Rubio, $\mathrm{M}^{\mathrm{a}}$ del Rosario, «Emilio Castelar et la culture française: chroniques littéraires et sociales d'un illustre voyageur espagnol», en L. FournierFinochiaro \& T.-I. Habicht (dir.), Gallomanie et gallophobie. Le mythe français en Europe au XIXe siècle, Rennes, Presses Universitaires de Rennes, 2012, pp. 177-192.

AránEGa, Francisco Miguel \& José Antonio SERrano, «La princesa de Solms, condesa Rattazzi y marquesa de Rute, Marie Laetitia Bonaparte-Wyse: genealogía de la princesa rebelde», Trastámara, 9 (2012), pp. 127-152; <http://www.everyoneweb.es/trastamara> [consulta: 15 marzo 2014].

Bonaparte-Wyse, Olga, The Spurius Brood: Princess Leticia Bonaparte and her Children, Londres, Victor Gollanez, 1969.

BRowne, Julius Henri, «A Peculiar Princess», The Galaxy, 20:3 (1875), pp. 348358; <http://digital.library.cornell.edu/> [consulta: 15 marzo 2014]; reproducido en The Esoteric Curiosa, 2 de octubre de 2012; <http://theesotericcuriosa. blogspot.com.es/> [consulta: 15 marzo 2014].

Delaville, Camille, «Mes contemporaines. Madame de Rute (née princesse Marie-Lætitia Bonaparte-Wyse)», Le Constitutionnel, 19 y 20 de enero de 1887; <http://gallica.bnf.fr> [consulta: 15 marzo 2014]; reproducido en C. Delaville, Mes Contemporaines, París, Sévin, 1887.

ESTEVE, Luis. El pensamiento de Emilio Castelar, Alicante, Universidad de Alicante, 1990 (tesis doctoral en microficha).

FouQue, Corinne, «Marie-Laetitia Studolmine de Solms, Rattazzi, de Rute, née Bonaparte-Wyse», Arts et Mémoire, 13 (1999), pp. 32-47.

Gómez-García Plata, Mercedes, «Antonio Machado y Álvarez (Demófilo): un précurseur incompris?», en S. Salaün (ed.), Entre l'ancien et le nouveau: le socle et la lézarde (Espagne, XVIIIe-XXe s.), París, CREC-U. de la Sorbonne Nouvelle, 2010, 566-596; <http://crec-paris3.fr/publications-du-crec/publications-en-ligne> [consulta: 15 marzo 2014]

HARSANY, Zoltan-Étienne, Marie de Solms (1831-1902), femme de lettres, Aix-lesBains, Imprimerie Multi 73, 1983.

IRVINE, Margot, «Un réseau de femmes journalistes: les collaboratrices aux Matinées espagnoles», en Ch. Planté \& M.-E. Thérenty (eds.), Masculin/Féminin dans la presse du 19e siècle, Lyon, Presses Universitaires de Lyon (en prensa).

JimÉnEZ Morales, María Isabel, «Entre la crónica de viajes y la autobiografía: Mi romería de Emilia Pardo Bazán», en $\mathrm{M}^{a}$ del M. Gallego \& E. Navarro (eds.), Relatos de viajes, miradas de mujeres, Sevilla, Alfar, 2007, pp. 155-180; <www. cervantesvirtual.com> [consulta: 15 marzo 2014].

LAFARGA, Francisco, «Femmes journalistes et femmes nouvellistes dans la revue Les matinées espagnoles (1883-1888)», en C. Palacios \& P. Méndez (eds.), 
Femmes nouvellistes françaises du XIXe siècle, Berna, Peter Lang, 2013a, pp. 235-247.

LAFARGA, Francisco, «Teatro francés y teatro en francés en la revista Les matinées espagnoles (1883-1888)», Anales de Filología Francesa, 21 (2013b), pp. 123136; <http://revistas.um.es/analesff/article/view/188181/155031> [consulta: 15 marzo 2014].

LAROUSSE, Pierre, «Rattazzi, comtesse», en VV. AA., Grand dictionnaire universel du XIXe siècle, París, Larousse, 1875, XIII, p. 730a-b; <http://gallica.bnf.fr> [consulta: 15 marzo 2014].

MARTINI, Magda, Une reine du Second Empire, Marie Laetitia Bonaparte-Wyse, Ginebra, Droz, 1957.

MCDermott, Patricia, «El proceso pardobazaniano de traducir y revisar un texto de historia literaria: "La nouvelle génération de romanciers et conteurs en Espagne" (La Revue), "La nueva generación de novelistas y cuentistas en España" (Helios)», La Tribuna. Cadernos de Estudio da Casa-Museo Emilia Pardo Bazán, 7 (2009), pp. 307-371.

PÉrez Romero, Emilia, «L'Espagne dans les articles d'Emilia Pardo Bazán pour la Nouvelle Revue Internationale», La culture de l'autre: l'enseignement des langues à l'université, Lyon, École Normale Supérieure-La Clé des langues, 2010; <http://cle.ens-lyon.fr/espagnol/> [consulta: 15 marzo 2014].

PÉrez Romero, Emilia, «Autotraducción del cuento Nieto del Cid; algunas notas sobre las dos versiones propias española y francesa de E. Pardo Bazán», en VV. AA., Escritura(s) y reescritura(s) en el mundo hispánico. II congreso internacional BETA (en prensa).

Sanz Morales, Manuel, «Emilio Castelar y los clásicos de Grecia y Roma», Cuadernos de Filología Clásica. Estudios latinos, 24:1 (2004), pp. 149-184.

SECRET, Jean, Mme de Solms-Rattazzi et son groupe littéraire en Savoie sous le second Empire, Aix-les-Bains, Armand, 1935.

SuE, Eugène, Une page de l'histoire de mes livres, Bruselas, Librairie Internationale, 1857.

VITU, Auguste, La vérité sur Madame Rattazzi, París, Degorce-Cadot, 1869; <http:// gallica.bnf.fr> [consulta: 15 marzo 2014].

Fecha de recepción: 02/04/2014

Fecha de aceptación: 13/11/2014 